\title{
Meditações da finitude em Ivan Junqueira
}

\author{
Alamir Aquino Corrêa (UEL)
}

RESUMO: O poeta Ivan Junqueira retoma um tema de Augusto dos Anjos ao tratar da morte como algo inevitável. O "saber a pêsames" enquanto estética denota a manutenção da elegia pastoral como forma poemática de grave interesse. A contemplação do silêncio mortuário enquanto reflexo de um eu-lírico ensimesmado corporifica a sua humanidade em tempos de desapego e de desprezo. O contexto é aquele de uma ressaca das mortes da Grande Guerra, de um afastamento do holocausto, quando parece esvaziada a noção da morte impensável da vida sem valor; por outro viés, é ele o poeta de uma melancolia exasperada pelo esvaziamento de um futuro inalcansável. A morte, em Ivan Junqueira, é motivo de uma tristeza incompreensível.

PALAVRAS-CHAVE: morte, poesia, Ivan Junqueira, luto.

ABSTRACT: The poet Ivan Junqueira retakes a theme from Augusto dos Anjos dealing with death as something inevitable. This taste of grief as an aesthetic denotes the maintenance of pastoral elegy as a poetic form of serious interest. The contemplation of the mortuary silence as a reflection of a self-absorbed I-lyric gives meaning to his humanity in times of disdain and indifference. The context is the undertow of the deaths during the Great War, of a removal from holocausto, when it seems to void the notion of the unthinkable death of life without value; for another bias, he is a poet of a melancholy enraged for the emptied and unreachable future. The death, in Ivan Junqueira, is the reason of an incomprehensible sadness. KEYWORDS: Death, poetry, Ivan Junqueira, grief.

Há algum tempo venho me dedicando a um estar-para-a-morte, na busca acadêmica de uma compreensão do impacto do tema na literatura e nas artes. Esse estar é menos uma consciência da finitude e mais uma afirmativa da arte enquanto aquela que nos revela a nós mesmos. Não creio que eu possa dar conta de tudo aquilo que li e deixei de perceber antes, ao retomar as percepções e impressões críticas ao longo de uma trajetória que se quer fazer já madura. Entretanto, antes de um ser-para-a-morte, quero continuar dizendo o que vejo de humano, talvez a condição mais diferenciadora do que somos, na morte enquanto tema e constância na arte, observando-a enquanto recurso estético que foge ao contexto da realidade extra-ficcional. Em suma, minha intenção é observar o objeto artístico, na esteira do estranhamento proposto por Viktor B. Shklovsky, enquanto manifestação crítica e reflexiva sobre a qualidade do humano.

A morte, enquanto fato social representado na literatura e nas artes, caminhou por várias searas e preocupações. Pode-se detectá-la na noção do julgamento do ser e do 
estar ainda na Antigüidade, especialmente entre os egípcios, no judaísmo (a oração recupera os pecados levando a alma para fora do Gehinnom, o nome dado na Torá ao espaço de espera e purga, para que entre no Gan Eden), já na primeira cristandade e no islamismo (Alá mudará o mal para o bem se houver arrependimento), quando a vida terrena organiza os destinos do além-da-vida. A idéia de uma atitude a ser punida está no fundamento da constituição da sociedade, de forma a propiciar a preservação mútua no convívio das cidades, respeitadas através da ética a propriedade e a vida.

Durante a Idade Média, muito em função de uma medicina claudicante ainda por demais ligada à crença nos desígnios divinos enquanto organizadores do destino dos homens e mulheres, mantida assim a noção de pecado para motivo de julgamento ainda em vida, surge uma percepção consoladora da morte coletiva, encontrável principalmente na pintura e na gravura, e retratada exemplarmente no Decameron de Boccaccio. Outro motivo recorrente, a Dança da Morte é a niveladora, pois todos podem ser levados pela Indesejada das gentes, desprezados o gênero, a condição social ou a idade. Fica sempre a noção da transitoriedade e do memento mori como articuladora da redenção de almas.

A morte na ocidentalidade chegou aos séculos XVIII e XIX como uma compreensão da individualidade libertária, principalmente através da consciência maior da razão científica, demonstrada pelas novas posturas urbanas (caso dos cemitérios e das vacinas) e entrou no século XX como o esvaziamento do indivíduo em prol de um anonimato proporcionado pelas grandes guerras. A memória coletiva se torna, especialmente enquanto monumento, o único registro simbólico daqueles que foram; pari passu, surge uma morte asséptica negadora do poder divino da medicina e distanciada da família e da tradição do vivente, reservando-se nos hospitais e asilos a solidão dos moribundos.

Formalmente, na ars moriendi representada nas obras artísticas, houve manifestações de júbilo, de orgulho, de indignação, de dó e terror, de continuidade e de espanto. Na singeleza dos infortúnios coletivos, aqui e ali pontuam as dores individuais tornadas banais ou desproporcionalmente insignificantes na sua totalidade singular, mas que juntas causam a sensação do horror em face do desumano. Na literatura, encontramse diversas formas que vão desde os gêneros públicos, caso do sermão, do elogio de 
corpo presente ou fúnebre e da oratio funebris, até os gêneros épico-narrativos (Memórias Póstumas de Brás Cubas e São Bernardo, por exemplo) e poético-líricos ("Cântico do Calvário" de Fagundes Varela e "Morte no avião" de Drummond). Nesse trabalho interessa-me, particularmente, a elegia enquanto forma poemática e o seu papel na modernidade.

A elegia (grego E $\lambda \varepsilon \gamma i ́ \alpha)$ é um poema, geralmente composto de dísticos elegíacos (hexâmetro seguido de pentâmetro), para expressar lamento na morte de alguém ou por vezes uma tristeza qualquer, no caso de guerra ou de amores; por vezes também há o treno (poema sobre o morto cantado em qualquer lugar, como é o caso de Ariel sobre o pai morto de Ferdinando em $A$ Tempestade [I.ii] e de Fidele/Imogen em Cymbeline [IV.ii] de Shakespeare) ou lamento. São conhecidas as seguintes variantes: nênia (canção sobre aquele que se foi cantada por pranteadoras) ou epicédio (poema lamentoso sobre o morto presente), endecha (Lapesa 1979: 145) ou romancilho (com versos curtos) e epitáfio.

A elegia é o constructo poético capaz de organizar dores, ausências e memórias, com a vontade de explicitar um possível alento aos deixados, na sequiência do ovidiano hora fugit, por vezes sendo usado em epitáfios, como é o caso registrado na Lira I de Marília de Dirceu: "Quem quiser ser feliz nos seus amores, / Siga os exemplos, que nos deram estes". A qualidade da elegia depende muito da aceitação do assunto nela contido pelo leitor como verdade e testemunho (Shaw 1994). Na literatura clássica, em razão de sua qualidade métrica há vários exemplos de elegias acerca da coletividade, como é o caso de Simonides de Ceos e Simonides de Amorgos, acerca dos heróis de Maratona e da Batalha das Termópilas: "Vá, diga aos Lacedemônios, passante, / que aqui obedientes a suas leis restamos" $\underline{1}$

Depois do Renascimento, a elegia assume - talvez em prol de um reconhecimento da individualidade - o caráter mais singular, como expressão de dor acerca da morte de um ente querido (Camacho Guizado 1969). Estabelece-se como um ubi nunc ou ubi sunt qui ante nos fuerunt, a perguntar onde estão aqueles que eram. Os lamentos por pessoas específicas são comuns, transformados na convivência moderna pelos testemunhos televisivos de dor do passamento de figuras públicas. 
A elegia geralmente busca sua constituição na variante pastoral, cuja origem remonta aos poetas clássicos Teócrito (Theocritus e "Thyrsis"), Moscos de Siracusa (Moscus e "The Lament for Bion") e Bíon de Esmirna (Bion e "The Lament for Adonis") (Edmonds 1912). Nela, o poeta e o pranteado são pastores, invocam-se as musas e entes mitológicos são trazidos como paisagem mesclada à Natureza, os guardiães do morto são questionados pelo poeta sobre o que faziam quando da visita da Morte, há uma procissão de lamentadores; o poeta então discorre sobre a justiça divina e as maldades, há uma cena da flor a emoldurar o esquife e finalmente percebe-se uma renovação da esperança, contida na morte o começo de nova vida (Cuddon 1992: 273). Na modernidade, o aspecto pastoral perde evidência, mas enfatiza-se a reflexão pessoal, como é o caso do longo poema "When Lilacs Last in the Dooryard Bloom'd" de Walt Whitman.

Recentemente, com a velocidade das informações mediáticas, talvez seja possível outro olhar, na esteira dos episódios começados com o 11 de setembro. Entretanto, o registro elegíaco parece ser a forma mais apropriada que a arte encontra para lidar com a emoção da finitude. Esse século tem, por variadas razões, um distanciamento do que se convencionou nas elegias fundadas no sentimento de redenção religiosa. Para compreender isso, ou seja, como uma forma ou um gênero criado em determinada necessidade transforma-se, enquanto ato de fala, visite-se a posição de Tzvetan Todorov em sua teoria da origem dos gêneros:

o fato de uma obra 'desobedecer' a um gênero não faz com que este desapareça; é tentador dizer que o contrário realmente é verdadeiro. E por uma razão de dois termos. Primeiro, por conta da transgressão, para existir como tal, necessita de uma lei que possa ser, claro, transgredida. . . . Mas há mais. Não apenas a obra, por ser exceção, pressupõe necessariamente uma regra; mas essa obra também, tão logo seja reconhecido o seu status excepcional, torna-se por sua vez, graças a boas vendas e atenção crítica, uma regra. $(160)^{2}$

A elegia, na modernidade, tem a marca de outra qualidade, transgredindo as leis anteriores, a buscar não mais a da salvação mas a registrar aquela do desespero pela impossibilidade da aceitação do desumano. As guerras, em sua crescente capacidade destrutiva, separam a morte da esperança, pois nada resta; possivelmente, o artista deixa 
de acreditar na continuidade da vida para a morte, destruindo o continuum e enfatizando a dualidade entre vivos e mortos. A falência do humano é, em ultima res, a própria falência do divino, pois não poderia um Deus permitir tamanha desproporção quando o homem nega a sua própria humanidade; em termos formais, talvez possa se dizer que a modernidade não encontraria mais na elegia clássica um de seus fundamentos, na tradição pastoral, o locus amoenus. Há uma transformação, mantidas as condições:

Apesar das mudanças do motivo nas versões clássicas, cristã e romântica, emergem dois temas estáveis. Primeiro, o locus amoenus é sempre uma imagem poética imaginada, que permite ao poeta criar alguma versão de um reino ideal, que está bastante distante das dificuldades dolorosas do mundo real. Por meio da criação imaginária de uma paisagem desejada, o poeta realmente controla e transforma a sua rudeza em um lugar que é adequado à harmonia e habitabilidade humana. Segundo, o locus amoenus oferece um ideal que permanece inatingível pois existe apenas na linguagem. (Haas 1998: 673-74) $)^{\frac{3}{}}$

A esperança de uma salvação torna-se improvável por sua inexistência, ou seja, o salvador torna-se imponderável diante de seu afastamento dos homens que se mostram desumanos - e não há como evitar a lembrança de En Attendant Godot, de Samuel Beckett. Mantém-se então não a esperança de uma salvação, mas a idéia utópica da esperança; não mais a esperança do que não se pode esperar, mas a esperança como possibilidade, não mais a ênfase na circularidade mas sim a verdade da vida como uma crueldade aceitável. Parece ter se perdido o conceito de morte como a transição entre o mundo real e o mundo místico. Talvez isso possa ser explicado pela efetiva participação da ciência e da razão no mundo moderno. Isso não caracteriza uma ausência de religiosidade; tampouco há elementos que sustentem um veio mais forte e firme acerca do comprometimento de uma moral a justificar a vida terrena em face de uma punição ulterior, ou seja, no além-da-vida.

Em síntese, percebe-se no contexto, uma dificuldade moderna de lidar com a morte, enquanto conceito de uma metafísica religiosa. Cada vez mais individulizante, a voz lírica discute o morrer e a morte, enquanto processos angustiados, tristonhos, melancólicos, como se nos faltasse o chão e permanecêssemos de pé. A inevitabilidade da morte, manifestada enquanto memória do ubi sunt,transforma-se em mistério indevassável, por falta de completo sentido da vida. Essa sensação caótica organiza-se, 
pelo paradoxo, pelo apego à vida, como se tivéssemos de dar um valor maior ao que temos vez que não há mais certeza do que teremos.

Por este ângulo, lembro aqui do poeta Ivan Junqueira que retoma, em várias de suas obras, uma tradição de Augusto dos Anjos ao tratar da morte como algo inevitável. A poesia de Ivan Junqueira é também inevitavelmente uma peça canônica, não apenas por seu percurso continuado de poeta, mas especialmente por sua sagração institucional. Jornalista, critico literário, ensaísta, tradutor de poetas pilares da modernidade (Baudelaire e Eliot), teve carreira pontilhada por prêmios expressivos, alcançando a eleição para a cadeira 37 da Academia Brasileira de Letras, sucedendo João Cabral de Melo Neto, também artífice do poema moderno. Sua obra poemática começa em 1964 com Os Mortos; desde então, publicou Três Meditações na Corda Lírica (1977), A Rainha Arcaica (1980), Cinco Movimentos (1982); O Grifo (1987); A Sagração dos Ossos (1994), Poemas Reunidos (1999); Os Melhores Poemas de Ivan Junqueira (2003) e Poesia Reunida (2005).

Sua fortuna crítica é composta principalmente de notícias em jornais; a sua técnica rítmica e o seu apuro melódico parecem ter encantado críticos que geralmente apontam os seus textos como essenciais, singulares, articulados, eivados de uma tradição da lírica luso-brasileira, mas bebendo em outras fontes, especialmente por sua convivência com os estrangeiros que traduziu. Seus leitores são parte do que tem sido a melhor critica literária dos cadernos "dois" dos jornais brasileiros desde a década de 60; cito entre vários por ordem de sobrenome Almeida Fischer, Assis Brasil, Walmir Ayala, Ivo Barroso, Aurora Bernardini, Rubem Braga, Alexei Bueno, Antonio Candido, Geir Campos, Otto Maria Carpeaux, José Castello, Edilberto Coutinho, Fausto Cunha, Helena Parente Cunha, Paulo Francis, José Lino Grünewald, Antônio Houaiss, Ledo Ivo, Bella Joseph, Leandro Konder, Stella Leonardos, Oswaldino Marques, Wilson Martins, José Guilherme Merquior, Carlos Nejar, Antônio Olinto, Fernando Py, Olga Savary, Donald Schüller e Elizabeth Veiga. Saltam aos olhos, entretanto, três textos tipicamente acadêmicos: Gilberto Mendonça Telles e seu artigo “As Duas Vozes do Poeta" especialmente ao tratar da técnica do parénthesis em Junqueira (prefácio de $A$ Rainha Arcaica), "O exato exaspero" de Antonio Carlos Secchin (prefácio de $A$ 
Sagração dos Ossos) e a dissertação de Ricardo Luiz de Souza, orientado de Secchin, "Uma poesia com vísceras: o palimpsesto poético de Ivan Junqueira".

Se é que é possível dizer algo de diferente, em face de tal fortuna critica, registro em Ivan Junqueira o "saber a pêsames" enquanto estética que denota a manutenção da elegia pastoral como forma poemática de grave interesse. Interessa-me assim observar a contemplação do silêncio mortuário enquanto reflexo de um eu-lírico ensimesmado, corporificando a sua humanidade em tempos de desapego e de desprezo. O contexto é aquele de uma ressaca das mortes da Grande Guerra, de um afastamento do holocausto, quando parece esvaziada a noção da morte impensável da vida sem valor; por outro viés, é ele o poeta de uma melancolia exasperada pelo esvaziamento de um futuro inalcançável. A análise que farei procurará evidenciar a morte, em Ivan Junqueira, como motivo de uma tristeza incompreensível.

Tite de Lemos, em 1964, ao tratar de Os mortos, levanta a idéia de que o poeta deve enfrentar a sua própria morte, de maneira intuitiva, pois cabe ao poeta "pensar o mundo" (268). Esta barreira, de fundo metafísico, sobre a finitude, amplia na modernidade a compreensão do constrangimento da solidão, enfrentável pelo mundo dos deixados. A tônica deixa de ser o ubi sunt do solitário e passa a ser a incompreensão da tristeza que os mortos nos causam, pela memória que deles carregamos, logo um hic sunt:

E por que tanto sigilo em vosso verbo melífluo, se a morte em si já é signo transfigurado de vida,

se apenas um morto em mim é o que basta de agonia para que o tempo o redima e logo inverta a sua sina? $(27-28)$

Lembro aqui de um dos poemas mais sólidos da contrição cristã na literatura brasileira, o soneto "A Jesus Cristo Crucificado estando o poeta para morrer" de Gregório de Matos. No caso, o soneto gregoriano estipula, falando com Cristo, "Se basta a vos irar tanto um pecado, / A abrandar-vos sobeja um só gemido"; também falando com o morto crucificado, Gregório organiza a sua relação de morte próxima. $\mathrm{Na}$ 
versão elegíaca de Junqueira, falando com os mortos, a memória do vivo ou do deixado se incomoda com a redenção dos mortos, nos vivos invertida a sua sina. Por outro lado, lidar com a morte, que para muitos pode soar como crueldade, é ter e recuperar a consciência da Todestanz ou Dance Macabre, pela convivência com o escatológico da memória que não os compõe na sua inteireza:

Lembro alguns, talvez meninos que se foram por equívoco; e outros mais, algo esquecidos que de sim mesmos se iam.

Mas estes, a que família de mortos pertenceriam? A que clã, se não os sinto Visíveis, tampouco extintos?

Ou quem sabe não seriam mortos de morte, mas sim de vida: imagens em ruínas na memória adormecidas. (26-27)

Esse momento da reflexão sobre a indissociabilidade entre a vida e a morte retorna em $O$ Grifo, apontada por Per Johns no prefácio desta obra. Talvez pela própria idéia de um grifo, guardião de tesouros, mistura de força e precisão, pautadas pela dureza dos golpes, o eu-lírico se afasta da festividade ritualística da morte para a crueza da realidade da morte, conjunto de efervescência da vida que destrói o que se foi, na destruição apocalíptica da revelação mais íntima e profunda: "Desde o princípio o grifo tudo arruína / — sonhos, idéias, êxtase, delírio — / e até no poema a sua língua bífida / enfia em busca do que lhe é mais íntimo" (142), infalível na sua espera:

(...). A grande ave,

Pousada sob os galhos, aguarda

Aquele que virá matá-la, para depois

Aos poucos devorar-lhe a inútil alma

E a carne consumir-lhe palmo a palmo (147)

Na mesma obra, Ivan Junqueira tenta dividir corpo e espírito em "Corpus meum" (148150). Propõe ele uma dualidade e não uma continuidade, como se pudéssemos separar uma coisa da outra, em contraste com o conceito de carnalidade enquanto invólucro, vil 
matéria que retornará ao pó ("pasto de vermes e moscas / que lhe degustam os livores. / Este corpo, este meu corpo... / Que a terra lhe seja fofa"). Lembra Cruz e Sousa em "Cárcere das almas" e até mesmo Fernando Pessoa no quinto poema de "As Quinas" de “O Brasão" de Mensagem, intitulado "D. Sebastião, Rei de Portugal” quando falando com um eu-lirico de D. Sebastião sobre sua loucura, pede que a vejam "Sem a loucura que é o homem / mais que besta sadia, / cadáver adiado que procria”.

A idéia de um julgamento fundado em regras compreensíveis e pré-acordadas deixa de ter substância. Alguns poemas mantêm a elegia como memória dolorosa ou como manifestação de carinho ao morto. É o que acontece em "Pompas Fúnebres":

\author{
(A quem pertence o espírito \\ desse corpo tão franzino \\ em cujas lívidas linhas \\ lê-se - último capítulo?) \\ A morte tudo ilumina, \\ Mesmo em pleno meio-dia \\ À sombra da pirâmide, \\ O tempo é como a areia \\ E lento se esfarinha. (183)
}

Uma tônica que perpassa vários poemas é a discussão sobre o morrer. Se antes era a noção do conforto ou do consolo aos deixados ou uma preventiva argumentação sobre a boa qualidade do morto em vida, passa tal preocupação a ser com o viver oposto ao não viver, como em "A Sagração dos Ossos”:

Onde andaram? Em que solo deitaram sêmen e prole? Foram químicos, astrólogos, remendões, físicos, biólogos?

Ou nada foram? Que importa não haja um só microscópio lhes cevado a magra forma ou a mais ínfima nódoa?

Existiram. Esse é o tópico que aqui, afinal, se aborda. $\mathrm{E}$ eis que o faço porque, ao toque de meus dedos em seus bordos tais ossos como que imploram 
a mim que os chore e os recorde que jamais os deixe à corda da solidão que os enforca.

[...]

Baixa uma névoa viscosa Sobre as pálpebras da aurora. E ali de pé, sob a estola de um macabro sacerdote,

Sagro estes ossos que, póstumos, recusam-se à própria sorte, como a dizer-me nos olhos: a vida é maior que a morte. (262-263)

Outra tensão importante é a construção do depois do morrer. Lembro aqui que uma das características fundamentais da elegia é permitir que haja, mesmo em face do infortúnio da perda, uma esperança. A modernidade parece ter encontrado um formato especial - ao tratar da morte como um episódio individual mas não individualizado. Ou seja, a morte e a perda enquanto motivos do lamento se tornam mais universais no sentido de haver na voz lírica do poema moderno um foco no que ouve a sua fala. Ivan Junqueira nega uma após-a-vida, em "Morrer", fazendo sentir que não há muito a dizer: "Pois morrer é apenas isto: / cerrar os olhos vazios / e esquecer o que foi visto" (313). O eu-lírico desmistifica a morte, organizando-a por sua completa falta de utilidade: "é talvez como despir / o que em vida não vestia / e agora é inútil vestir"; a vida mesma deixa de ser, a morte é, sem ser: "é findar-se como um círio / em cuja luz tudo expira / sem êxtase nem martírio" (314).

Nós, vivos, e nós, mortos, acabamos perdidos em nós mesmos, divididos entre o ser e o estar, o primeiro impossível e o segundo transitório - assim, resta-nos buscar conviver com o que nos sobra, lembrando que há uma ótica do deixar desde Mateus 8:21-22, que os mortos enterrem seus mortos, ou nas palavras do eu-lírico de Ivan Junqueira, em “O Enterro dos Mortos” (208):

Não pude enterrar meus mortos.

Sequer aos lábios estóicos lhes fiz chegar uma hóstia que os curasse dos remorsos.

Quero esquecê-los. Não posso: 
andam sempre à minha roda, sussurram, gemem, imploram e erguem-se às bordas da aurora

em busca de quem os chore ou de algo que lhes transforme o lodo com que se cobrem em ravina luminosa.

\section{Notas}

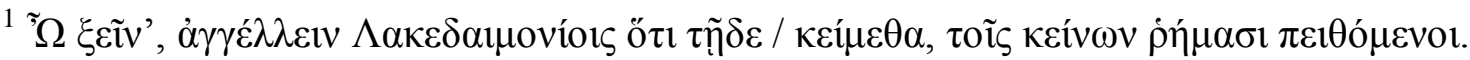

${ }^{2}$ The fact that a work 'disobeys' its genre does not make the latter nonexistent; it is tempting to say that quite the contrary is true. And for a twofold reason. First, because transgression, in order to exist as such, requires a law that will, of course, be transgressed. . . . But there is more. Not only does the work, for all its being an exception, necessarily presuppose a rule; but this work also, as soon as it is recognized in its exceptional status, becomes in its turn, thanks to successful sales and critical attention, a rule.

${ }^{3}$ Despite the changes in the classical, Christian, and Romantic versions of the motif, however, two stable themes emerge. First, the locus amoenus is always an imagined, poetic activity that allows the poet to create some version of an ideal realm that is far removed from the painful difficulties of the real world. By imaginatively creating the landscape of one's desires, the poet, in effect, controls nature and transforms its wildness into a realm that is suitable for human harmony and habitation. Second, the locus amoenus offers an ideal that remains unattainable because it exists only in language.

\section{Obras citadas}

Camacho Guizado, Eduardo. La elegia funeral em la poesia española. Madrid: Gredos, 1969.

Cuddon, J. A. The Penguin Dictionary of Literary Terms and Literary Theory. London: Penguin Books, 1992.

Edmonds, J. M. trad. The Greek Bucolic Poets. Loeb Classical Library Volume 28.

Cambridge, MA. Harvard Univserity Press, 1912.

Haas, Robert Bernard. "The Mutable Locus Amoenus and Consolation Tennyson's In

Memoriam."Studies in English Literature 1500-1900 38.4 (agosto 1998): 669-87.

Junqueira, Ivan. Poemas Reunidos. Rio de Janeiro: Record, 1999.

Lapesa, Rafael. Introducción a los estudios literarios. Madrid: Cátedra, 1979.

Shaw, W. David. "Elegy and theory: is historical and critical knowledge 
possible?” Modern Language Quarterly 55.1 (March 1994): 1-16.

Todorov, Tzvetan. "The Origin of Genres." New Literary History 8 (1976): 159-170. Whitman, Walt. Leaves of Grass. Philadelphia: David McKay, [c1900]; Bartleby.com, 1999. Disponível em http://www.bartleby.com/142/192.html; acesso em 14 de junho de 2008. 